\title{
Working
}

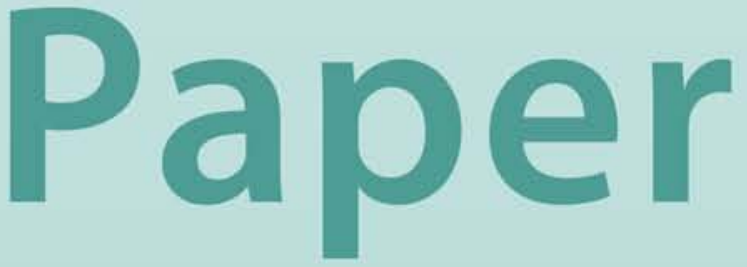


The Complier Pays Principle: The Limits of Fiscal Approaches Toward Sustainable Forest Management

Luc Leruth, Remi Paris, and Ivan Ruzicka 


\title{
IMF Working Paper
}

Fiscal Affairs Department

\section{The Complier Pays Principle: The Limits of Fiscal Approaches Toward Sustainable Forest Management}

\author{
Prepared by Luc Leruth, Remi Paris, and Ivan Ruzicka ${ }^{1}$ \\ Authorized for distribution by Sanjeev Gupta
}

March 2000

\begin{abstract}
The views expressed in this Working Paper are those of the author(s) and do not necessarily represent those of the IMF or IMF policy. Working Papers describe research in progress by the author(s) and are published to elicit comments and to further debate.
\end{abstract}

This paper examines the role and impact of taxation on sustainable forest management. It is shown that fiscal instruments neither reinforce nor substitute for traditional regulatory approaches. Far from encouraging more sustainable forest management, fiscal instruments such as an inappropriate tax policy can actually undermine it. The paper uses the arguments at the root of the Faustmann solution to draw conclusions on the incentives for sustainable tropical forest exploitation. The paper also proposes a bond mechanism as an alternative market-based instrument to encourage sustainable forest logging while reducing monitoring costs.

JEL Classification Numbers:H32, Q23, Q28, R38

Keywords: Environment, Sustainable management, forestry taxation

Author's E-Mail Address:LLeruth@imf.org, Remy.paris@oecd.org, nuzicka@iprolink.ch

${ }^{1}$ Remi Paris, Head of Section, Environment and Sustainable Development, Development Cooperation Directorate at the OECD; and Ivan Ruzicka, applied economist, Vovray-enBornes, France. This paper was initiated in 1998 when the first author was a professor at the University of Liège and at CORE, Catholic University of Louvain, Belgium. The authors are thankful to P. Chander, J.H. Drèze, R. Gillingham, S. Gupta, J. Ligthart, L. de Mello, $\mathrm{V}$. Reppelin, and $\mathrm{S}$. Rietbergen for suggestions and comments. 


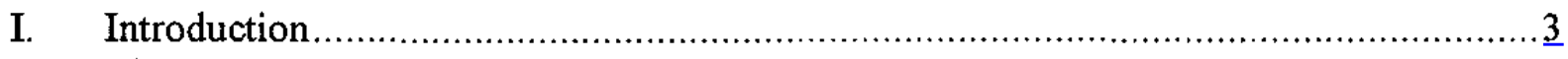

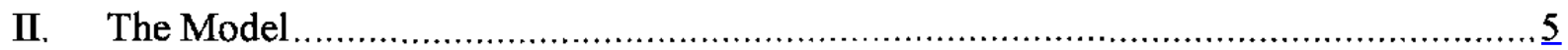

III. The Agent's Problem................................................................................. 11

IV. The Effect of Taxes on Forest Management .................................................. 15

V. Fiscal Approaches to Forest Management: The Implicit Assumptions...................... 18

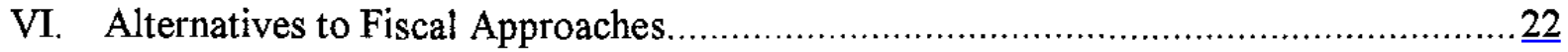

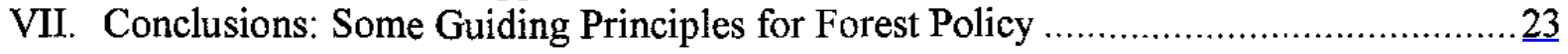

\section{Figures}

1. Stock of Wood: Law of motion with three equilibria......................................... $\underline{8}$

2. Stock of Wood: Law of motion with two equilibria ........................................... $\frac{8}{8}$

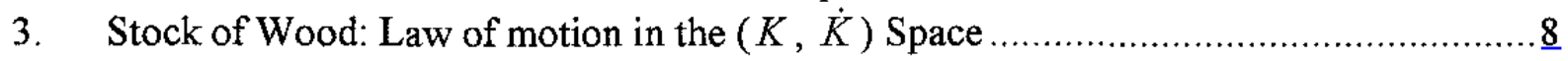

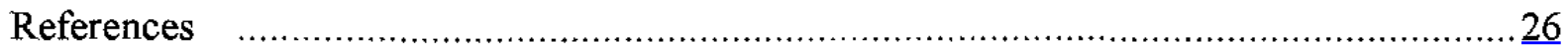




\section{INTRODUCTION}

Sound natural resource management that takes into account long-term social, ecological, and economic values and functions is an essential component of sustainable development strategies. The recurrent fiscal imbalances affecting many developing countries have created an urgent need for government revenue and renewed pressure to tax natural resources. Indeed, despite genuine concerns about past patterns of resource depletion and degradation in many developing countries - and the impacts at the local, national, and global levelsnatural resources remain one of the most easily accessible sources of revenue in times of hardship. ${ }^{2}$

Natural forests, which are viewed by many governments as a ready source of fiscal revenue, are particularly at risk. Where they are still found, they often represent the ecologically, and economically, optimal use of the land, and provide a wide range of nonmarket ecological services in addition to timber and nontimber products. ${ }^{3}$ Their degradation through overexploitation generally implies an economic cost far beyond the loss of timber production potential. $^{4}$

Policy analyses attributing forest depletion to insufficient taxation have, unfortunately, pointed to a virtuous complementarity between increasing fiscal revenue collection and improved forest management. ${ }^{5}$ Simply put, it was argued that loggers (cast as polluters) could be induced to internalize the full social cost of their activities through a tax on timber extraction. The argument was that the "Pigovian" tax used to limit pollution was applicable to forestry. ${ }^{6}$ The idea that a tax could generate greater revenue while simultaneously fostering improved sound natural resource management was, and largely remains, very attractive indeed. The resulting policy prescriptions, superficially based on the "polluter pays principle," have often been embraced by international development institutions, which have

\footnotetext{
${ }^{2}$ In Honduras, state forestry revenue accounted for less than 1 percent of central government revenue in 1994, but stumpage prices increased by a factor of five in two years. In Cameroon, forestry taxes accounted for 3.5 percent of revenue in 1998/99, up from 2.5 percent three years before. In the Philippines, total taxes on logs increascd from .06 percent of revenue in 1989 to .4 percent in 1991 (World Bank, 1999).

${ }^{3}$ These "external benefits" range from the preservation of soil stability and regulation of hydrological cycles to the provision of habitats to a large number of species.

${ }^{4}$ Where natural forests can be converted to superior uses (e.g., as agriculture or tree plantations) even when all their external benefits are taken into account, deforestation should be thought of as welfare-enhancing land improvement. Where this is the case, the arguments developed in this paper do not apply.

${ }^{5}$ See Repetto (1988); Hyde and Sedjo (1992); and Vincent (1993a and b).

${ }^{6}$ The Pigovian tax can be defined as a tax set as the difference between the marginal social and marginal private cost of an externality-generating agent that restores efficiency in resource allocation.
} 
encouraged their clients to make increased timber taxation the cornerstone of forest management policies. ${ }^{7}$

To a large extent, fiscal approaches to improved management are presented as effective alternatives to traditional command-based and control-based regimes centered on the monitoring and enforcement of quantitative logging rules which have proved to be largely ineffective.

After more than a decade of experience, the policies appear to have been moderately successful on the fiscal side. Although they have been implemented in earnest only after the bulk of accessible areas of forest had disappeared, increased forest taxation has begun to yield significant amounts of fiscal revenue in many countries (though still accounting for a small percentage of revenue, as mentioned in footnote 2). However, they have not had any noticeable positive impact on forest management, and indications are that forest degradation from commercial timber exploitation has continued unabated in many countries. ${ }^{8}$

This paper examines the role and impact of taxation on sustainable forest management by commercial operators. ${ }^{9}$ We derive a policy-adjusted Faustmann solution to the problem of forest management and show that fiscal instruments neither reinforce nor substitute for traditional regulatory approaches. There are numerous reasons for this, both practical and theoretical. The most fundamental is that the relationship between the environmental damage resulting from logging is weakly and indirectly related to the volume of timber sold. A given level of exploitation can lead to very high or very low environmental damage, depending on a complex combination of factors ranging from logging techniques, to site-specific characteristics such as topography and proximity to urban centers. Thus, the basic requirement for Pigovian fiscal instruments to work, namely the possibility that a levy on the socially damaging activity could narrow the distortion between the private and social costs of the activity, is not satisfied. We also point to a number of practical reasons which further undermine the case for fiscal instruments as a means of enforcing logging rules. ${ }^{10}$

\footnotetext{
${ }^{7}$ Paris and Ruzicka $(1991,1993)$ are a dissenting voice while Vincent and Panayotou (1994) offer a detailed account of the evolution of thinking over time.

${ }^{8}$ In addition, there is also a danger of corruption both on the part of the logger and the government. We do not systematically review this issue, but the interested reader is referred for example to Contreras-Hermosilla (1997), or to documents produced by the Environmental Intelligence Agency (1996).

${ }^{9}$ We focus exclusively on the case of commercial loggers. Community-based forest management schemes require a completely different set of measures which are not covered in this paper.

${ }^{10}$ We effectively argue that the "ceteris paribus" assumption, which would require all other variables in play to remain unchanged following the imposition of a levy, is simply untenable. Only strict regulation could force loggers to keep all other factors unchanged following the imposition of a tax. Thus, regulatory enforcement is actually a precondition for the tax to be levied as envisaged exante. Given the wide scope and incentives for violation, the levics themselves increase the need for strict monitoring and enforcement. The same conclusion powerfully emerges from virtually all recent assessments of industrial environmental taxation (e.g., Harvard Institute for International Development, 1999).
} 
Furthermore, we show that, far from encouraging more sustainable forest management, fiscal instruments can actually undermine it. An inappropriate tax policy could generate more damage to the resource than no tax at all and the environment under any set of real world assumptions. Based on this analysis, we present proposals for alternative regulatory instruments.

The paper is organized as follows. Sections II and III present the model and derive its properties, identifying the conditions necessary for sustainable forest management. These conditions are shown to be consistent with the Faustmann solution, ${ }^{11}$ well known to students of classical plantation forestry. Section IV provides a formal analysis of the issue of taxation and its implications for forest management in the tropics, as well as policy advice. Section $\mathrm{V}$ reviews in further detail some of the key assumptions underlying fiscal approaches to forest management, so as to highlight the sharp divergence of the current orthodoxy with some basic facts. In Section VI an alternative policy instrument is proposed, which overcomes these limitations. Section VII concludes the paper.

\section{THE MODEL}

Consider a natural forest containing a population of trees belonging to overlapping generations (at different stages of maturity). For simplicity, we assume that all these trees belong to the same species. ${ }^{12}$ Left in a natural state, old-growth forest remains at an equilibrium with no net increment of timber stock over time. This is because all available nutrients and light are fully utilized. Following an external shock, such as a fire or a storm, the standing stock naturally generates a recovery back to equilibrium.

Under these conditions, it is possible to harvest trees selectively as they become mature without endangering the forest regenerative capacity and without having to replant the trees felled. The selective logging regimes prescribed in most tropical countries are designed precisely to ensure that the natural reproductive capacity of the forest is preserved. ${ }^{13}$

\footnotetext{
${ }^{11}$ In its simplest form, the Faustmann solution states that the logger will cut trees up to the point where the forest will grow at the interest rate.

${ }^{12}$ In reality, forests contain a wide variety of species corresponding to different classes and grades of timber. This has been given much attention in the early literature on the subject (see Page, Pearson, and Leland, 1976). Plotted against unit prices, the composition of each typical arca can be organized in a descending order, the most valuable segment of the commercial stock first, followed by the second most valuable, etc. The resulting set of species-specific horizontal demand curves is often refcrred to, wrongly, as the demand schedule. This schedule is useful, however, for the examination of the impact of changes in the structure of species-specific timber taxes on the mix of species harvested. In this paper, we consider species heterogeneity as a distraction relative to the definition of policies fostering sustainable forest management as a whole.

${ }^{13}$ These rules are normally translated into limits on the minimum diameter of trees cut. Increasingly, common requirements for forest managers to replant trees following felling effectively assume a violation of selective logging rules.
} 
Sustainable exploitation effectively implies removing the naturally generated increment of mature timber at each period. ${ }^{14}$ Overharvesting can, however, destroy the ability of the forest to regenerate naturally if the stock of remaining trees falls below a certain threshold, causing the forest to completely disappear unless a compensating human intervention, such as replanting, takes place.

We first assume that the stock of wood $K_{t}$ in the forest at time $t$ evolves between $t$ and $t+1$ according to the following general rule: ${ }^{15}$

$\mathrm{K}_{\mathrm{t}+1}=\left[\mathrm{K}_{\mathrm{t}}\right]^{\alpha(\mathrm{K} t)}$

where the exponent can be written as

$\alpha\left(\mathrm{K}_{\mathrm{t}}\right)=\mathrm{B}-(\mathrm{B}-1) / \mathrm{A} * \mathrm{~K}_{\mathrm{t}}$

with $0<\mathrm{A}<1, \mathrm{~B}>1, \mathrm{~B}^{*}(1-\mathrm{A})<1$.

This rule yields a law of evolution represented in Fig. 1 and implies three equilibria:

[1] $\mathrm{K}_{\mathrm{t}+1}=\mathrm{K}_{\mathrm{t}}=1,[2] \mathrm{K}_{\mathrm{t}+1}=\mathrm{K}_{\mathrm{t}}=0$ and [3] $\mathrm{K}_{\mathrm{t}+1}=\mathrm{K}_{\mathrm{t}}=\mathrm{X}$;

with $\mathrm{X}$ given by the implicit equation $\mathrm{X}=\mathrm{X}^{\mathrm{B}-(\mathrm{B}-1) / \mathrm{A}^{*} \mathrm{X}}$

The first equilibrium is stable and corresponds to the long-term equilibrium of a minimally disturbed forest. The second equilibrium is also stable and corresponds to the complete degradation of the forest. The third equilibrium defines the threshold level of stock below which the forest will disappear (converge to the second equilibrium). Provided the stock does not fall below the threshold, the forest will regenerate following natural or man-made disturbances and eventually converge back to the first equilibrium. ${ }^{16}$

\footnotetext{
${ }^{14}$ As noted above, the conversion of a heterogeneous tropical forest into a tropical plantation, say rubber, eucalyptus, or another similar plant can be sustainable if the additional revenue thereby generated compensates for the loss of the timber and nontimber values generated by the natural forest. We concentrate here on the sustainable management of natural forests, and the associated environmental benefits. This excludes the possibility that converting natural forests to even-aged plantations would yield socially, economically, and ecologically superior results.

${ }^{15}$ This functional form has been used by economists in a number of different applications. See for example Clark, 1990.

${ }^{16}$ Removing aging trees releases light and space for younger ones and actually increases forest productivity. Certain operations like timber stand improvement can also lower the threshold.
} 
Since our focus is on regulating forest logging rather than on subsidizing plantations to replace degraded forests, we restrict ourselves to the region above the threshold $\mathrm{X}=\mathrm{X}^{\mathrm{B}-(\mathrm{B}-1) / \mathrm{A}^{*} \mathrm{X}}$. The model can then be simplified and written as:

$\mathrm{K}_{\mathrm{t}+1}=\left[\mathrm{K}_{\mathrm{t}}\right]^{\alpha}$

where $\alpha$ is a constant $<1$ (see Fig. 2).

This simplified rule yields only two equilibria:

[1] $K_{t+1}=K_{t}=1$ and [2] $K_{t+1}=K_{t}=0$.

The first equilibrium corresponds to the long-run stable equilibrium. The second equilibrium is not stable but the absence of stability has no effect on the analysis because any deviation from it, no matter how small, results in the forest regenerating itself. For the sake of clarity, we provide an alternative representation of the same rule in Fig. 3, possibly more familiar to noneconomists.

Consider now the case of an agent (the forest manager, or the lessee) who is granted by the principal (the government, or the lessor) the right to manage a given area of forest for a period of time. ${ }^{17}$ The period of time considered is assumed to span several rotation cycles. ${ }^{18}$ The agent is granted by the principal the right to cut trees from the existing stock in exchange for an initial fee, D, paid in full at the beginning of the lease. At the end of the tenure, the agent will receive a terminal payment $\mathrm{F}$. We shall discuss the nature of $\mathrm{D}$ and $\mathrm{F}$ later. Finally, we shall assume that, during his tenure, the agent will cut wood and sell it on the world market where he will be a price taker. ${ }^{19}$

Our task now is to explore the relationship between the terms of the lease, notably the lessor's fiscal policies, and the agent's behavior.

\footnotetext{
${ }^{17}$ In most developing countries, forest land is owned by the government and leased out to private logging firms.

${ }^{18}$ Rotation cycles will be dcfined here as the ideal length of time separating consecutive harvests of the same timber stand.

${ }^{19}$ This important assumption is consistent with the situation prevailing in the world timber industry as well as most national markets, where producers are small relative to the market as a whole.
} 
Figure 1. Stock of Wood:

Law of motion with three equilibria

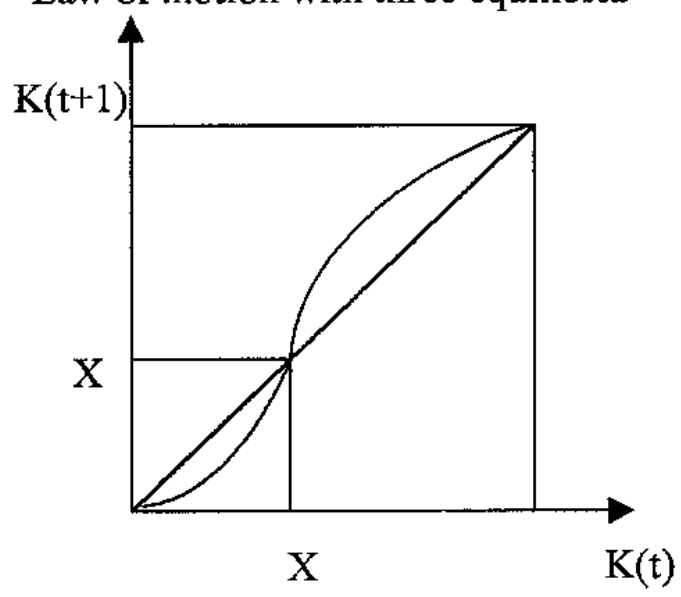

Figure 2. Stock of Wood:

Law of motion with two equilibria

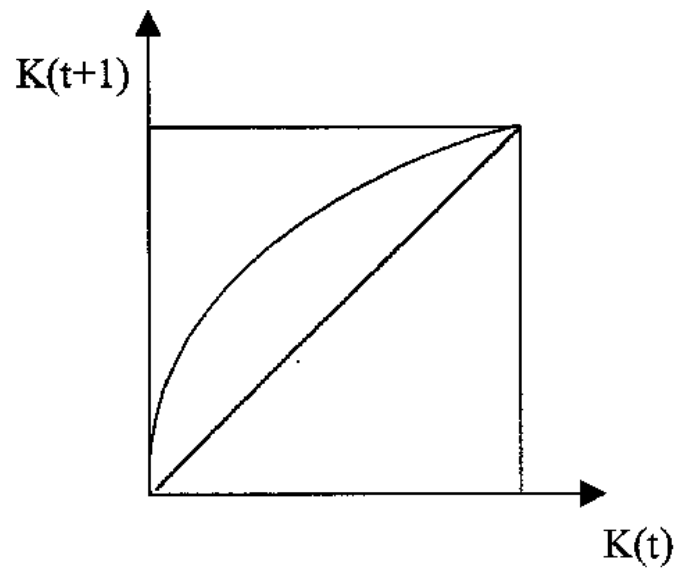

Figure 3. Stock of Wood:

Law of motion in the $(\mathrm{K}, \mathrm{K})$ space

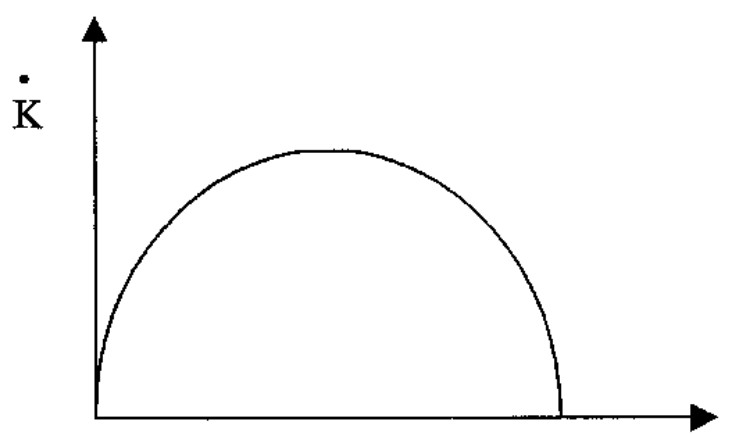

K 
In order to fell the trees, the agent must create physical access to them. In an ageheterogeneous forest (a population of trees, as opposed to an even-aged plantation and under a selective logging system), creating physical access to the forest, and felling and transporting logs out of it inevitably results in some damage to the residual stand (immature trees that are not meant to be harvested) ${ }^{20}$ In other words, each unit of timber sold results in a greater reduction in the stock of timber remaining in the forest.

The extent of this collateral damage depends on the harvesting and transport technology used. $^{21}$ The overall cost of bringing a unit of timber to the market rises in parallel with the efforts made to reduce the damage to unharvested trees. In general, the agent has a choice between a technology that is costly per tree sold, but which inflicts relatively little damage on unharvested trees ("helicopter logging"), or another relatively cheaper per unit sold, but entailing a bigger waste because more trees are effectively destroyed for each one actually sold ("bulldozer logging").

We shall assume that each tree cut to be sold costs $c$ per unit and that the felling process generates some damage to the forest. ${ }^{22}$ Let $\mathrm{Q}^{\text {sold }}$ be the quantity of wood effectively sold on the market and $\mathrm{Q}^{\text {cut }}$ be the quantity of wood cut (the sum of the quantity sold plus the amount of wood wasted in the process). As argued above, the choice of technology implies that

$\mathrm{Q}^{\text {cut }}=\mathrm{Q}^{\text {cut }}\left(\mathrm{Q}^{\text {sold }}\right)$, with $\partial \mathrm{Q}^{\text {cut }} / \partial \mathrm{Q}^{\text {sold }}>0$ and $\left.\partial \mathrm{c} / \partial \mathrm{Q}^{\text {cut }}\right\rfloor \mathrm{Q}^{\text {sold }}<0$.

Thus, for any given quantity of wood sold, it is possible to decrease the unit cost by inflicting increased damage to the forest (increasing $\mathrm{Q}^{\text {cut }}$ ). To preserve the tractability of our model, we will assume that

$\mathrm{Q}^{\text {cut }}=\gamma^{*} \mathrm{Q}^{\text {sold }}$, with $\partial \mathrm{c} / \partial \gamma<0$

\footnotetext{
${ }^{20}$ See, for instance, Borhan, Johari, and Quash (1987); and Cassel (1992).

${ }^{21}$ The term "technology" is a simplification. The cost of harvesting and the resulting damage to the residual stand will be determined not only by the choice of equipment used to reach, fell, and remove the trees (helicopters vs. bulldozers) but also by the way logging operations are planned and executed. Clearly, two different managers using the same technology may have a different impact on the forest stock according to their know-how and their approach. This means that the flexibility of response each agent has is far greater than suggested by the mere changes of technology more narrowly conceived. It also means that the imposition of qualitative logging rules as part of selective logging systems cannot be reduced to the prescriptions of specific types of equipment to be used. Over a longer run, the choice of technology will affect also the magnitude of the environmental cost, notably in the form of soil erosion resulting from logging (see Weidelt and Banaag (1992); Bruenig (1996); Munoz-Braz and d'Oliveira (1997); or ITTO (1996)).

22 This cost variable is a simplification. It amalgamates pre-harvest, harvest, and post-harvest costs without distinguishing between their variable and fixed components. This point is addressed in a later section.
} 
The cost function used here is very different from that generally used in models of renewable resources management where costs are associated with the effort required to extract the resources (Clark, 1990). Here, we focus on the amount of damage inflicted on the forest in order to extract a given quantity of timber for sale on the market. This difference has important implications that will be discussed in the course of the paper.

We now briefly turn to fiscal policy. Let us postulate that, as part of his lease, the lessee must also pay a number of logging-related taxes. We shall assume two different types of taxes: a stumpage fee $\mathrm{t}^{s}$ levied on the quantity of timber sold $\mathrm{Q}^{\text {sold }}$, and a waste $\operatorname{tax} \mathrm{t}^{w}$ on the volume actually removed from the stock through collateral damage but not sold $\left(Q^{\text {cut }}-Q^{\text {sold }}\right){ }^{23}$ In addition, the lessee pays an up-front lump sum fee $D$ and receives a lump-sum transfer at the end of the lease, as already mentioned. One could give several interpretations to these two variables. For example, $D$ could result from an auction bid by competing potential lessees eager to manage the forest. In that case, $D$ would reflect the discounted flow of net revenues expected by the (second) highest bidder. Similarly, F could be the result of an auction held at the end of the lease period for new prospective lessees and thus also reflect the value and volume of the stock of wood available in the forest and the end of the lease. When the lessor is the government, D could play the role of a guarantee bond or a "deposit" demanded from the logger and returned at the end of the lease if the logger has managed the forest according to agreed criteria. In this case again, both $\mathrm{D}$ and $\mathrm{F}$ will depend upon the stock of wood at the beginning and at the end of the lease. Finally, D could be interpreted as an area tax paid up front and never returned. In that case, although $F$ would also be paid by the next logger, it would not enter into the profit function of the current one. We shall explore these possibilities later as appropriate.

We now turn to the interpretation of the other variables introduced in the model.

$\mathrm{Q}^{\text {sold }}$, the quantity of timber sold, represents a homogeneous commodity, namely marketablesized trees, and is readily observable. Furthermore, it is easy to attribute an indisputable monetary value to $\mathrm{Q}^{\text {sold }}$ at any point in time, by reference to an observed market price which is independent of the origin of the trees concerned.

$\mathrm{Q}^{\text {cut }}$, which includes $\mathrm{Q}^{\text {sold }}$ as well as the quantity of timber removed or otherwise destroyed in the course of extracting $\mathrm{Q}^{\text {sold }}$, is a heterogeneous mix: it includes marketable trees damaged in the course of the harvest as well as immature trees damaged during or after the harvest. Some of these immature trees may be very far from maturity at the time they are destroyed. $\mathrm{Q}^{c u t}$ is not readily observable, although we assume a linear relationship between the quantities sold and cut for the sake of our argument. The fact that the quantity cut is not observable implies that $\gamma$ is not observable, since $\mathrm{Q}^{\text {cut }}=\gamma^{*} \mathrm{Q}^{\text {sold }}$.

\footnotetext{
${ }^{23}$ Assuming that a waste tax can effectively be levied. Adding a tax on income would not affect the results in any way.
} 
Even if $\gamma$ were observable, it would not be possible to attribute an indisputable money value to the quantity actually cut, because this would require a perfect knowledge of the age and diameter of all trees damaged, their future volume growth rate, their market price at the time when they reach marketable age, and the rate of interest in the intervening period. For the same reason, it is not possible to attribute a market value to the stock of wood $\mathrm{K}$ discussed at the beginning of the section. ${ }^{24}$

\section{The Agent's Problem}

In order to develop the argument gradually, we shall at first assume that $\gamma$, reflecting the technology used, is fixed. For a given technology-and associated cost structure and $\mathrm{Q}^{\text {cut }} / \mathrm{Q}^{\text {sold }}$ ratio- the problem of the lessee is to maximize the discounted flow of profits during the period of the lease. For the sake of simplicity, we shall first write the continuous problem for an infinite lease. Unless otherwise specified, we assume that both $\mathrm{Q}^{\text {cut }}$ and $\mathrm{Q}^{\text {sold }}$ are calculated at time t. We have:

$$
\max \Pi=\max \int_{0}^{\infty} \mathrm{e}^{-\delta \mathrm{t}}\left[\left(\mathrm{p}_{\mathrm{t}}-\mathrm{c}-\mathrm{t}^{\mathrm{s}}\right) \mathrm{Q}^{\text {sold }}-\mathrm{t}^{\mathrm{w}}\left(\mathrm{Q}^{\text {cut }}-\mathrm{Q}^{\text {sold }}\right)\right] \mathrm{dt}-\mathrm{D}
$$

which, since for any time $t, Q^{\text {cut }}=\gamma^{*} \mathrm{Q}^{\text {sold }}$, can be written as

$\max \prod=\max \int_{0}^{\infty} \mathrm{e}^{-\delta t}(\mu / \gamma) \mathrm{Q}^{c u t} \mathrm{dt}-\mathrm{D}$

where $\mu$ is the net margin, such that

$\mu=p_{t}-c-t^{s}+t^{w}(1-\gamma)$

In order to solve this problem, we introduce the stock of wood in the forest $K_{t}$ at time $t$, which is determined by the law of motion as

$\mathrm{K}_{\mathrm{t}+1}=\left[\mathrm{K}_{\mathrm{t}}\right]^{\alpha}-\mathrm{Q}^{c u t}$

or

$\Delta \mathrm{K}=\left[\mathrm{K}_{\mathrm{t}}\right]^{\alpha}-\mathrm{K}_{\mathrm{t}}-\mathrm{Q}^{\text {cut }}$.

This will allow us to rewrite the profit maximization problem as an Euler equation:

\footnotetext{
${ }^{24}$ Recall that we have considerably simplified matters by assuming a single species. More realistic assumptions would make it even more difficult to assign a market value to $\mathrm{Q}^{\text {sold }}$ and $\mathrm{K}$.
} 
$\max \prod=\max \int_{0}^{\infty} \mathrm{e}^{-\delta \mathrm{t}}(\mu / \gamma)\left(\left[\mathrm{K}_{\mathrm{t}}\right]^{\alpha}-\mathrm{K}_{\mathrm{t}}-\dot{K}\right) \mathrm{dt}-\mathrm{D}=\max \int_{0}^{\infty} \Phi(\mathrm{t}, \mathrm{K}, \dot{K}) \mathrm{dt}-\mathrm{D}$

Thus we know that the optimal harvesting policy in the steady state must follow

$$
\frac{\partial \Phi}{\partial K}=\frac{d}{d t} \frac{\partial \Phi}{\partial\left(\frac{d K}{d t}\right)}
$$

which leads to the well-known Faustmann rule (see also Mitra and Wan, 1986):

$\alpha \mathbf{K}^{\alpha-1}=1+\delta$

The interpretation of this law is also well known: the agent cuts wood in such a way that the rate at which the remaining stock regenerates is equal to the interest rate (adjusted for risk and other factors). If we solve this equation, we obtain the equilibrium harvesting solution given by $^{25}$

$$
\mathrm{Q}^{\mathrm{cut}}=\mathrm{K}^{\alpha}-\mathrm{K} ; \mathrm{K}=\left(\frac{1+\delta}{\alpha}\right)^{\frac{1}{\alpha-1}} ; \text { or } \mathrm{Q}^{\text {cut }}=\left[\left(\frac{1+\delta}{\alpha}\right)^{\frac{\alpha}{\alpha-1}}-\left(\frac{1+\delta}{\alpha}\right)^{\frac{1}{\alpha-1}}\right]
$$

As a preliminary to the discussion of the discrete case, we make the following important point. The solution obtained above applies only in the steady state. In general, however, the lease does not start with a stock of wood just equal to the equilibrium stock $\mathrm{K}^{\wedge}=\left(\frac{1+\delta}{\alpha}\right)^{\frac{1}{\alpha-1}}$. If the stock is higher, the agent will be able to extract more wood during the first period than during the subsequent ones. ${ }^{26}$ If the stock of wood is lower, the agent will have to wait for the number of periods required to bring it up to the equilibrium level $\mathrm{K}^{\wedge}$. In fact, it is possible to compute the amount of time required to reach equilibrium when the initial stock is $\mathrm{K}_{0}$. The easiest way to do so is to use a discrete approach and compute the number of periods $n$ required as satisfying:

$$
K_{0}^{n \alpha}=\left(\frac{1+\delta}{\alpha}\right)^{\frac{1}{\alpha-1}}=\mathrm{K}^{\wedge}
$$

\footnotetext{
${ }^{25}$ Note that the Euler equation obtained here is a special case of the more general solution where the effort made to harvest the stock has an impact on costs (e.g., where $c$ increases with the quantity cut). The interested reader should refer to Clark, 1990, p. 40.

${ }^{26}$ Actually, faster harvesting could extend for several periods if the technology does not allow undertaking harvesting operations throughout the lease area. We rule out this possibility in the formal model, but will occasionally discuss it.
} 
and thus

$\mathrm{n}=\frac{1}{\alpha} * \ln \left(\left(\frac{1+\delta}{\alpha}\right)^{\frac{1}{\alpha-1}}-K_{0}\right)$

Let us now consider the case of a finite discrete lease running from $0 \mathrm{to} t=\mathrm{T}{ }^{27}$ The previous discussion suggests that we must have $\mathrm{T}>\frac{1}{\alpha} * \ln \left(\left(\frac{1+\delta}{\alpha}\right)^{\frac{1}{\alpha-1}}-K_{0}\right)$ so that the agent has a possibility to reach the equilibrium harvest. ${ }^{28}$

The agent's problem now becomes

$\max \prod=\max \left[\sum_{t=0}^{T} \frac{1}{(1+\delta)^{t}} \mu * Q^{\text {sold }}-D+\frac{F}{(1+\delta)^{T}}\right]$

where $\mathrm{F}$ is the amount received by the agent at the end of the lease, if any.

First note that if $F$ is a constant, by which we mean that it is not linked to the value of the stock remaining in the forest at time $\mathrm{t}=\mathrm{T}$, the logger will cut the whole stock of wood during the last period. ${ }^{29}$ This is particularly true if $F=0$. Thus, unless there is an enforcement mechanism by a public body, an assumption we do not make, for reasons discussed at length in the paper, a profit-maximizing logger will not leave a positive stock of wood at the end of the lease without financial compensation. However, if there is a mechanism by which the remaining stock is properly valued, not only will the logger have an incentive to leave the forest at equilibrium, there will also be no need for an enforcement agency. This is one immediate, simple, and yet very important policy conclusion of our model. It also directly implies that if the lessor wants the agent to behave in a sustainable manner (such that he harvests the increment only throughout the lease), the end-of-lease transfer must correspond to the value of the concession at the end of the lease, which is the discounted flow of profits for the new logger under competitive bidding. We shall come back in more detail to this critical point, but we can already see that a mechanism by which proper valuation is maintained at the end of the lease can replace costly (and often ineffective) enforcement efforts. In particular, the bond mechanism discussed later (see also Paris and Ruzicka, 1994) would provide a market-oriented and efficient mechanism to ensure sustainability. In fact, the

${ }^{27}$ The duration of forest leases must also be consistent with the exceptionally long rotation periods involved. Many timber species mature only after $20-25$ years or more.

${ }^{28}$ Clark (1990) presents a detailed discussion of what happens when the length of the lease is such that the equilibrium harvest is never reached.

${ }^{29}$ That is, if, as mentioned earlier, the technology makes this possible. If not, the logger will deplete as fast as possible toward the end of the lease so that $K_{t}$ vanishes at time $t=T$. 
same mechanism is at the root of the Faustmann equation at the steady state: it is because he knows that he will extract some profits during the remaining period of the lease that the logger does not cut the whole stock at time $\mathrm{t}<\mathrm{T}$.

We shall therefore assume from now that the value of $\mathrm{F}$ is given by

$\mathrm{F}=\int_{0}^{\infty} \mathrm{e}^{-\delta \mathrm{t}}\left(\mu^{\prime} / \gamma\right) \mathrm{Q}^{c u t} \mathrm{dt}$

where we denote by $\mu$ ' the margin that the next logger is able to realize. Although we have not made it explicit, the technology used could also be different, and we could have $\gamma^{\prime} \neq \gamma$. If the current logger leaves the stock of wood at equilibrium at time $t=T$, the value of $F$ will be

$\mathrm{F}=\frac{\mu^{\prime}}{\gamma \delta} *\left[\left(\frac{1+\delta}{\alpha}\right)^{\frac{\alpha}{\alpha-1}}-\left(\frac{1+\delta}{\alpha}\right)^{\frac{1}{\alpha-i}}\right] * e^{-\delta T}$

Yet, as mentioned earlier, the current logger need not necessarily leave a stock of wood equal to $\mathrm{K}^{\wedge}$. W. Assuming that the logger leaves a stock $\mathrm{K}_{\mathrm{T}}<\mathrm{K}^{\wedge}$, we know that the next logger would then have to wait for a number of periods given by $\left\{\ln \left(\mathrm{K}^{\wedge}-\mathrm{K}_{\mathrm{T}}\right)\right\} / \alpha$ and therefore we have

$\mathrm{F}=\frac{\mu^{\prime}}{\gamma \delta} *\left[\left(\frac{1+\delta}{\alpha}\right)^{\frac{\alpha}{\alpha-1}}-\left(\frac{1+\delta}{\alpha}\right)^{\frac{1}{\alpha-1}}\right] * e^{-\delta\left(T+\frac{1}{\alpha} * \ln \left(K^{\wedge}-K_{T}\right)\right.}$

and we observe, as expected, that $\partial \mathrm{F} / \partial \mathrm{K}_{\mathrm{T}}>0 .^{31}$

On the other hand, by leaving a stock below equilibrium, the logger benefits from a large harvest at period $\mathrm{T}$. Thus, he must make an arbitrage between this extra income and the forgone amount it induces on $F$. In fact, at time $t=T$, the logger must maximize with respect to $\mathrm{K}_{\mathrm{T}}$ the following expression:

$\mu *\left[\left(\frac{1+\delta}{\alpha}\right)^{\frac{\alpha}{\alpha-1}}-K_{T}\right]+\frac{\mu^{\prime}}{(1+\delta) \gamma \delta} *\left[\left(\frac{1+\delta}{\alpha}\right)^{\frac{\alpha}{\alpha-1}}-\left(\frac{1+\delta}{\alpha}\right)^{\frac{1}{\alpha-1}}\right] * e^{-\delta\left(T+\frac{1}{\alpha} * \ln \left(K^{\wedge}-K_{T}\right)\right.}$.

\footnotetext{
${ }^{30}$ We refer here to the Bellman equations that are at the root of the Faustmann solution. Indeed, at every period $t$ in $] 0, T[$, the logger follows the same path (e.g., weighs the returns from his logging activities) at time $t$ and the returns from all remaining periods. For a detailed account, see Bellman (1957) or Clark (1990).

${ }^{31}$ We apologize for using discrete and continuous notations. However, this is done only for tractability and clarity and does not affect the results in any way.
} 
The first term expresses the extra benefit from overlogging during the last period (it is increasing if $\mathrm{K}_{\mathrm{T}}$ decreases) while the second represents the forgone lump sum $\mathrm{F}$ (which is decreasing if $\mathrm{K}_{\mathrm{T}}$ decreases). The expression above has two extrema: one in $\mathrm{K}_{\mathrm{T}}=0$, and one in $\mathrm{K}_{\mathrm{T}}=\left[\left(\frac{1+\delta}{\alpha}\right)^{\frac{\alpha}{\alpha-1}}\right]$.

Once again, this result has important implications, discussed in the next section. If, at the end of the lease, there is a high uncertainty regarding $\mathrm{F}$, or a certainty of low payment (one where the immediate benefits from overlogging exceed the expected benefit from keeping the forest in a sustainable state), the current agent will have a strong incentive to overharvest the forest, namely to cut trees which are still growing faster than the interest rate-and would become mature only after the lease has expired-so long as they can be sold on the market. ${ }^{32}$ If the probability of repayment falls to zero, the forest will necessarily be exhausted at the end of the lease. ${ }^{33}$ This outcome is quite consistent with frequently observed situations where forest leases neither provide a long-term security of tenure, allowing the operator to benefit directly from sustainable management practices during the lease period, nor reward for compliance with prescribed selected logging rules (in the form of a terminal payment). Conversely, if future timber prices are expected to be high, and the government is not expected to default, the agent may voluntarily leave behind a better stocked forest than at the beginning of the lease.

\section{The EfFect of TaXes on Forest Management}

The previous section suggests that by levying taxes, thereby affecting the level of profits (since $\mu=p_{t}-c-t^{s}+t^{w}(1-\gamma)$ ), the government has an impact on forestry management through two different, yet mutually reinforcing, mechanisms: the short-term equilibrium amount harvested by the logger changes; and the value of the remaining stock of wood, which determines the long-term sustainability of the forest, also changes. Note, however, that the two taxes considered here do not have the same impact. An increase in $t^{s}$, the tax on the quantity sold, decreases the margin irrespective of the technology used by the logger, while a tax on the amount wasted, if it can be implemented, penalizes wasteful management. Note too that the equilibrium value obtained for the quantity cut, given by

$$
\mathrm{Q}^{\mathrm{cut}}=\left[\left(\frac{1+\delta}{\alpha}\right)^{\frac{\alpha}{\alpha-1}}-\left(\frac{1+\delta}{\alpha}\right)^{\frac{1}{\alpha-1}}\right],
$$

\footnotetext{
${ }^{32}$ Generally, immature trees are salable at a discount, reflecting their smaller diameter.

${ }^{33}$ In practice, rising logging and transport costs owing to topographical factors and increased distance from the forest gate would eventually result in increasing the marginal cost of logging. The more remote parts of the lease area may thus not be worth logging and some marketable timber stock would still remain unharvested. These complexities do not affect our basic results.
} 
is not dependent on $\mu$ as long as the logger has an incentive to pursue sustainable management (as long as the Faustmann solution applies). We will show that this is not the case for $Q^{\text {sold }}$. However, we shall first consider the long-term impact of taxes on the value of the stock.

We have already shown that, toward the end of the lease, the logger will weigh the benefits of leaving a sustainable stock in the forest against the expected terminal payment. If the value of such payment falls below a certain level, the agent will deplete the forest. Among other factors (like the rate of discount, the technology used, or the probability of default), taxes play a critical role because they clearly affect future profits by reducing the value of the discounted flow of profits for the current agent as well as the transfer $F$ at the end of the lease. It is therefore evident that if taxes imposed today exceed a critical amount (defined as the level beyond which the Faustmann solution does not apply), there is no scope for sustainable forest management. Once the level of taxation is such that the Faustmann solution does not apply any longer, there will even be an increase in the quantity sold as the logger optimizes his income along the unsustainable path of forest depletion. Note too that the same conclusion would obtain if sufficiently high new taxes were suddenly imposed during the lease: the logger would simply deplete the resource in order to minimize costs and give up on the possibility of receiving $\mathrm{F}>0$ at the end of the lease. ${ }^{34}$

The impact of higher taxes on short-term forestry management where the level of profits remains compatible with the Faustmann solution is a little more complex to describe. First, since the equilibrium quantity of wood cut (not the quantity sold) in the forest remains unaffected by the level of the tax (as we have seen earlier), the only possible impact of a change in taxes is on the quantity sold in the market. This occurs through the strategic choice of technology by the logger $(\gamma)$ because $Q^{\text {cut }}=\gamma Q^{\text {sold }}$. The logger will adopt the technology that maximizes the margin for a given quantity cut. Thus, the agent actually maximizes with respect to $\gamma$ :

$$
\frac{\mu}{\gamma}=\frac{p_{t}-c-t^{s}+t^{w} *(1-\gamma)}{\gamma}
$$

where $c=c(\gamma)$. To analyze more precisely the link between tax policy and forest management, we therefore need to introduce explicitly the link between cost and technology:

$\partial \mathrm{c} / \partial \gamma<0$

For simplicity, let us now assume that

\footnotetext{
${ }^{34}$ As already emphasized, preventing such behavior is possible only with rigorous and, therefore, costly monitoring.
} 
$\mathrm{c}(\gamma)=\lambda / \gamma$, with $\lambda>0$

The value of $\gamma$ that maximizes the ratio $\mu / \gamma$ is given by $\gamma^{*}$ such that:

$\gamma^{*}=\frac{2 \lambda}{p-t^{s}+t^{w}}$

and

$c\left(\gamma^{*}\right)=\frac{\lambda}{\gamma}=\frac{p-t^{s}+t^{w}}{2}$.

This relationship clearly shows that a profit-maximizing agent compensates for increases in the stumpage tax by adopting cheaper but more wasteful technology. ${ }^{35}$ As expected, an increase in the waste tax has the opposite effect but, as later argued, is hard to implement. Only lessees whose intentions are to comply with logging rules (environmentally conscious lessees) will fail to avail of this ready means of increasing profits by relying on a cheaper technology. In other words, the tax burden falls on compliers rather than violators. Thus, the reduction in volume harvested and sold as a result of the tax is actually accompanied by increased forest destruction. By effectively reducing the value of salable trees, the stumpage tax makes it less worthwhile to harvest efficiently, and more mature and immature trees are destroyed in the logging process. Once again, only the expectation of a terminal payment can counterbalance the incentive to reducing costs. ${ }^{36}$ Assuming a fixed technology, which excludes this key adjustment mechanism, is therefore simply untenable. Note that the process of intensified forest degradation can coexist with increased collection of stumpage taxes and an observed reduction in the volume of timber reaching sawmills or harbors. ${ }^{37}$

Increased stumpage taxes $\mathrm{t}^{\mathrm{s}}$ would have the desired effect of reducing volumes cut, if and only if the lessor could control qualitative logging methods, a task even more resourceintensive and demanding than monitoring the agent's observance of quantitative (e.g., diameter limit) cutting rules. Also worth noting is that a stumpage tax expected to remain permanent would reduce the effectiveness of a terminal payment by counterbalancing the incentives to overharvest and minimize logging costs during the lease period. Thus, the

\footnotetext{
${ }^{35}$ The result follows from the assumption that the logger is a price-taker.

${ }^{36}$ Export taxes or bans, and any other measure reducing the market price of logs, have the same negative impact. Conversely, eco-labelling or export certification schemes that allow certified loggers to obtain higher prices for sustainably harvested timber encourage good logging practices.

${ }^{37}$ Typically, timber taxes are assessed not at the logging site, which would be very expensive, but at mill-gate. This further weakens the argument that these taxes encourage the enforcement of quantitative logging rules.
} 
effect of the tax is similar to an increase in the probability of default by the lessor. Even if we had assumed renewable leases and terminal payments $\mathrm{F}$, increased timber taxes would encourage forest degradation.

This leaves the waste tax $t^{\mathrm{w}}$ as the only effective instrument to foster sustainable logging practices. However, this possibility is theoretical. In practice, given the difficulty involved in either observing or attributing a ready monetary value to $K$, the assessment of a waste tax is far more demanding than a simple enforcement of quantitative logging rules, and most unlikely to be a practical option. The problem is compounded if the externality associated with $Q^{\text {cut }}$ is also taken into account, including a whole array of nonmarketed negative externalities both internal and external to the area. ${ }^{38}$ External environmental damage includes, in particular, soil erosion and loss of biodiversity whose values are area-specific. ${ }^{39}$ Setting the appropriate level for the quantity of wood cut and for the waste tax would require taking account of area-specific factors. A forest administration that has the capacity to enforce quantitative and quantitative logging rules with a fair degree of rigor would probably find a waste tax unnecessary and not worth the trouble.

\section{FisCal APPRoaches to Forest MANAGEMENT: THE IMPLICIT ASSUMPTIONS}

Traditional fiscal approaches toward improved forest management are based on a number of assumptions reviewed below.

\section{The tax as an incentive to conserve timber}

One assumption is that reducing the price received by loggers for each unit of timber felled will foster improved management. As we have shown formally, lowering the price of timber, through a stumpage tax (or any other instrument having the same impact, such as an export ban), has the opposite effect and encourages wasteful forest management. This results from two mutually reenforcing mechanisms: (i) the tax reduces the value of future harvests and therefore the incentive to preserve immature stock for the future; and (ii) the decline in revenue per unit further increases the incentives to compensate through reduced logging costs, leading to increased damage to the forest. The tax on the quantity of timber sold has

${ }^{38}$ The problem is further compounded by the complex nature of logging damage. Some of it is inflicted on trees that would be suppressed by competing trees (would die in any case). The measured volume of wood lost in the course of logging will therefore tend to overestimate the loss of future salable volume. Other complexities of tropical growth dynamics are beyond the scope of this paper. This also suggests that reliable measurcment of environmental damage in tropical forestry is more complex than in industrial applications where end-of-pipe measurements often suffice as a basis for a Pigovian pollution tax.

${ }^{39}$ The actual economic cost of watershed degradation and soil erosion is dependent on the nature and value of downstream infrastructure, notably road, power-generation, and irrigation facilities. It could be negligible in an uninhabited area and very severe in a densely populated urban zone. The damage to biodiversity will similarly depend on the species affected. Note that none of these arguments bears any relation to the market value of the timber extracted. 
the same effects as an increase in the interest rate or an anticipated decline in future timber prices, namely to encourage the liquidation of the asset.

The choice of sound management instruments must integrate the impossibility to dissociate harvesting activities from those aimed at generating future harvests. The resources spent on minimizing collateral damage in the course of logging must be assimilated to an investment in future harvest. For the sake of simplification, we have not placed much emphasis on the distinction between pre- and post-harvest logging costs. A more complex model would reflect the fact that maintaining forest productivity over the long term entails establishing durable infrastructure (roads) and protection measures (against man-made and natural shocks such as fire). Taking the usually high fixed costs of sustainable management into account necessarily implies a large difference between the cost structure of a long-term-minded logger and of a "fly-by-night operator," to the detriment of the former. This point is invariably overlooked in calculations of the profitability of logging, where only direct logging costs are included. In sum, any tax set at a level designed to collect the profits from a fly-by-night operator directly discriminates against long-term-minded operators who comply with qualitative rules at a high cost. ${ }^{40}$

This is not to deny that high net timber prices encourage logging. High logging profits generate pressures on governments to grant forest leases. The imposition of a tax may play a role in reducing such pressures. However, this will only succeed in taking the least commercially attractive sites out of production because they will no longer attract lessees, but will not improve the management of intramarginal forests which are leased out. At best, the positive effects of a timber tax are minimal. ${ }^{41}$

\section{The tax as a positive environmental incentive}

Another wrong assumption reflects insufficient understanding of the relationship between logging and environmental damage: each additional tree felled is assumed to result in additional environmental damage. If so, the socially optimal level of logging would be reached when the social or environmental cost resulting from the extraction of the marginal $\log$ equals the marginal net private value of the marginal log extracted. Following this logic, a tax should automatically reduce the environmental damage from logging by reducing the marginal benefit.

\footnotetext{
${ }^{40}$ Paris and Ruzicka (1991) discuss these questions in detail.

${ }^{41}$ The timber tax works only to the extent that it makes certain forests no longer worth logging. This will have positive environmental impacts if and only if the other factors behind forest degradation (notably conversion to subsistence agriculture or pastures by landless poor) are absent. If the areas put out of production because of the tax are large enough, it may lead to a rise in the price of timber. In this sense, its impact is different from an export ban, which would lead to a reduction in domestic timber prices.
} 
In reality, environmental damage resulting from logging is, at best, only weakly related to the volume of timber extracted. Within a given site, environmental damage is caused by excessive cutting intensities (in violation of quantitative rules as well as poor logging and road-building practices); and, in many cases, the abandonment of an area following harvest, allowing encroachment by slash-and-burn cultivators. As we have shown above, the imposition of a tax will have no positive impact on these factors and, by penalizing compliance with logging rules, can even have the opposite effect of encouraging outright forest liquidation. The impact of logging-related environmental damage, notably soil erosion and the destruction of immature stock, are borne first by the concessionaire in the form of considerably reduced subsequent harvests. For a long-term-minded logger who complies with qualitative logging rules. the divergence between private and social profits are not significant. By minimizing the impact of logging on immature stock, the operator will also minimize the off-site impacts. ${ }^{42}$ Conversely, a fly-by-night operator will generate severe onand off-site damage regardless of the volume harvested.

The idea that a tax could help equate the marginal profits from logging with the marginal environmental cost becomes even more problematic when the nature of off-site environmental damage attributable to logging is examined. First, off-site environmental damage in the form of severe watershed degradation is more closely related to the topographical features of areas logged than to the volumes extracted, (e.g., the consequences of land denudation is more severe in steeply sloped areas). Secondly, the time lag between logging activities and environmental damage downstream is considerable, often stretching over decades. The relationship between such environmental damage and the volume of timber extracted in upstream areas is difficult to measure. Thirdly, the actual economic impact of soil erosion, siltation and watershed degradation is a function of population density and the value of affected infrastructure (roads, canals) and not related to the profitability of logging. It is therefore possible for a logger operating in a highly fragile area to impose costs on downstream inhabitants far in excess of the financial profits generated by his activities and clearly in excess of the taxes collected. In such circumstances, the enforcement of logging rules in order to minimize damage is preferable to the imposition of a tax. If compliance with logging rules raises costs so as to make the operation unprofitable, an outright ban on logging is required. ${ }^{43}$

\footnotetext{
${ }^{42}$ The disturbance to forest biodiversity resulting from logging operations is a notable exception, because biodiversity is a public good which does not enter the loggers' private profit maximization. Special measures are therefore required. This is discussed further in Section VI.

${ }^{43}$ Reid and Rice (1997) suggest that natural forest management is not financially attractive in most countries of tropical Latin America. In view of the environmental benefits, they advocate susbsidies for natural forest management. They also suggest that such subsidies would have to be very large to close the gap in profits between uncontrolled logging and sustainable management, although others offer statistical evidence that careful logging can be profitable. The point is that environmentally sustainable logging cannot be measured by reference to the market price of logs. Paris and Ruzicka (1991) provide "guesstimates" of the difference between the financial and economic gains of logging in the Philippines.
} 


\section{Forests as a gift of nature}

Fiscal approaches somehow embody the notion that forests are a gift of nature and that the cash flows generated in harvesting them represent pure profit. As we have discussed above, the techniques involved in natural forest harvesting make it impossible to dissociate harvesting activities from those aimed at generating future harvests. The notion that the first harvest is somehow "free" (and taxable) is therefore incorrect even if one operates in a virgin forest. $^{44}$

The consequences of viewing forests as God-given resources and ignoring the cost involved in ensuring long-term productivity are more severe now than years ago. In many parts of the world, remaining "forests" are in fact a patchwork combining denuded areas, abandoned forest concessions at various stages of depletion, and adequately stocked areas where timber extraction continues, often illegally. To the extent that these areas cannot generally be converted to agriculture, the first priority is to arrest the continued process of degradation and restore productivity, where possible, through intensive management. Increasing taxation, combined with the provision of subsidies for the establishment of plantations, has the perverse effect of encouraging the outright conversion of still viable but degraded natural forests into monocrop plantations.

\section{Logging should be treated as a form of pollution}

Taxation-based approaches to environmentally sound forest management are built on a superficial similarity with industrial pollution. If a pollution tax is now firmly established as an appropriate instrument to deal with industrial pollution, we have seen that the same is generally not true for tropical logging. The majority of industrial pollution taxes is appropriately levied on the concentration or (better still) volume of the pollutants, and not on the volume of activities giving rise to the emissions. Environmental economists would be rightly concerned if, say, $\mathrm{SO} 2$ emissions by coal-powered power plants were to be dealt with by taxing the electricity produced instead of the SO2 emissions (or their precursors, such as the sulphur content of coal). The mirror image of industrial applications in the context of tropical logging would be taxes on logging damage, not on logging per se. By not distinguishing between a legitimate activity and its possible (although not inevitable) environmental side effects, some analysts have ended up favoring an exceedingly blunt and inefficient tax alternative.

\footnotetext{
${ }^{44}$ A closely related misconception is that the policymaker faces a choice between a pristine forest and an overlogged forest. This belief underlies arguments in favor of outright logging bans. In many parts of the world, notably in densely populated areas, the real alternative is between a managed forest or a forest degraded through encroachment and conversion to unsustainable slash-and-burn agriculture. This is not to suggest that the world's few remaining virgin forests do not deserve special treatment. In many cases, such forests should not be available for any kind of commercial logging activities, or only at a very high price, in view of their exceptional environmental, cultural, and social value.
} 


\section{ALTERNATIVES TO FISCAL APPROACHES}

To a large extent, distortions between the lessor and the lessee's interests are the predictable results of a divorce between ownership and management of forest resources, suggesting that full nationalization or outright privatization of forests may be the logical solution. The experience of government involvement in commercial activities cautions against the full nationalization solution. Conversely, the environmental services provided by forests (including biodiversity conservation, which may be in conflict with the logger's private interests), argue against the privatization solution, at least in environmentally sensitive areas. The real challenge is to devise instruments that provide maximum security of tenure to private lessees and credible means to enforce regulations to the lessor. This also implies confining the government to regulation and enforcement functions while entrusting the private sector with the actual tasks of managing and protecting forests areas.

Paris, Ruzicka, and Speechly (1994) outline a proposal for a forest guarantee bond which meets these requirements and draw lessons from initial implementation experience. ${ }^{45}$ The scheme aims to create a situation approximating that in an ordinary market where the owners of the resources benefit from good stewardship and suffer the consequences of bad management in the form of capital loss. In this paper, we have formalized their proposal and showed that it is not only compatible with the Faustmann solution, but actually built around the same principles. We also provided a formal proof of its economic and environmental soundness.

The forest guarantee bond ( $\mathrm{D}$ and $\mathrm{F}$ in our model) has the following main features: its value is established through competitive public bidding in an impartial and transparent market-based manner. The bond encourages responsible long-term management by the lessee because nondepleting behavior is rewarded by the return of the bond with accrued interest (in addition to which the lessee could, at any time, sell his rights appreciated by improvements) and, conversely it provides for the prompt punishment of the lessee (partial or complete forfeiture of the bond) and compensation for the government in case of violation of the terms of the agreement. This is in contrast to the traditional system in which the government's options are limited to the cancellation of the violator's license. The bond also provides a clear, market-based, indication of the profitability of forest management, and its risks in particular areas that command very low bonds (or no bids) and offer insufficient prospects for profits in view of the risks and responsibilities involved. These sites may be regarded as unsuitable for private management, and the government should consider subsidizing their protection. Finally, unlike the timber-royalty system, the scheme obviates the necessity for continuous field-level monitoring or evaluation of timber extraction rates because no charges are collected.

\footnotetext{
${ }^{45}$ Richardson (1992) makes a proposal along similar lines.
} 
In the context of our model, a bond scheme amounts to determining the initial payment $\mathrm{D}$ through an auction. The bidder willing to post the highest deposit, in guarantee of compliance, is awarded the lease. At the end of the lease, the forest is once again leased out and the resulting new value of $D$ reflects the increase or decline in value of the forest over the previous lease period. This provides a ready means of determining the terminal payment $\mathrm{F}$ to be returned to the first lessee. One lessee's up-front deposit becomes the previous one's terminal payment. A closely related alternative to this system would be to replace the upfront payment $D$ by a requirement for the lessee to insure himself against the risk of being found in violation of logging rules, like a third-party insurance common among car owners. The party willing to insure against that risk, for a fee, would then contract a contingent liability reflecting the damage caused to the forest in case of violation of logging rules by the lessee, and would compensate the lessor. The system would make it possible to discriminate against parties with a poor performance record, because insurers would refuse to cover them. The scheme is highly complementary with eco-labeling schemes for timber because the monitoring mechanisms required to assess compliance with the terms of the lease are identical to those required to award an eco-label.

\section{Conclusions: Some GuIDING Principles for Forest Policy}

Environmentally and economically sound logging implies respecting a number of concrete ecological and geophysical constraints which are weakly (if at all) related to either the volume or market value of the timber harvested. The concept of marginal environmental cost of logging has, therefore, little meaning, and taxes (other than a waste tax, which is difficult to monitor) can play no role in bringing marginal private and social cost into balance. The successful collection of (misnamed) environmental taxes on timber extracted is completely consistent with reduced timber extraction rates and accelerated environmental degradation. From a practical standpoint, the enforcement of sound forestry practices cannot dispense with on-site monitoring, reinforced, in many cases, by public oversight of forest authorities' performance. This monitoring must focus on the ecological state of the remaining forest, rather than on the flow of timber extracted, and this paper has shown that taxes on the flow of timber can neither substitute nor complement monitoring. The challenge is therefore to devise an incentive structure that encourages voluntary compliance with the ecological constraints necessary for continued forest health and long-term productivity, while minimizing the cost of indispensable on-site monitoring and enforcement. This has immediate relevance in regions such as Central Africa, where large areas of old-growth forests ( 1.8 million sq $\mathrm{km}$ ) are indiscriminately awarded for exploitation to private operators, with important negative environmental consequences.

In line with the rationale underlying the Faustmann solution, this paper has proposed a bond instrument which integrates the expected value of future harvests as the incentive for sustainable long-term forest management. The paper has shown that the bond provides the incentive for the logger to capitalize on his investment in future harvests while reducing the need for costly monitoring. 
The paper has also demonstrated that tax-based solutions hinge crucially on the regulators' ability to enforce logging rules strictly and control the logger's choice and use of technology. Because of this, the tax serves no management purpose. Given the wide scope for increasing profits through cheaper-though environmentally harmful-technology, tax-based approaches to forest management are based on untenable assumptions. Put another way, fiscal approaches to forest management assume the existence of a formidable capacity for field supervision instead of substituting for it.

Imposing taxes on volume extracted can serve (and indeed has served) as an effective revenue-raising device. However, it cannot be expected to inhibit forest depletion and degradation. In fact, increased timber taxation can accelerate forest degradation by penalizing compliance with logging rules intended to preserve forest health. Empirical observations of lower volumes of forest timber sales as a result of increased taxation is no evidence of improved forest management since higher tax and lower sales may mask increased volume cut.

Based on this analysis, we derive some guiding principles for sound forest policy. These principles are compatible with the proposed bond instrument, but are discussed below on the basis of their own merit.

\section{Maximize the opportunity cost of damaging immature stock}

The focus of forest regulation should be to maximize the value of immature stock for the lessee, thus encouraging sound logging practices, rather than to reduce the profit on timber harvested. In terms of our model, this implies that the terminal payment must be a fair reflection of the value of the forest at the end of the lease. Creating a market in immature stock by allowing rights to leases that have not yet expired to be traded (as with the bond) would reinforce this by allowing the lessor to realize the value of his investment in infrastructure and immature stock at any time during the lease.

\section{Maximize security of tenurial rights}

With some species maturing after more than 30 years, investments in immature timber stock, and the necessary forest management infrastructure, are exceptionally long term. Inevitable uncertainty about future timber prices, fluctuations in interest rates, and a host of other factors ${ }^{46}$ including vulnerability to natural disasters, make these investments rather risky. In addition to exogenous factors, the credibility of the lessor fundamentally affects the lessee's choice of technology and management approach. Even where a terminal payment is formally

\footnotetext{
${ }^{46}$ Deacon (1994) and (1995) suggests that an unstable macroeconomic environment has been an important factor of deforestation in many countries.
} 
included in the lease, lessees will have strong incentives to liquidate the forest as fast as possible if the government is believed to be prone to canceling the concession arbitrarily or without compensation (as amply evidenced throughout the forest concession history in the tropics). The fact that the credibility of the lessor can never be taken for granted poses special challenges in the design of regulatory instruments.

\section{Provide ready means to penalize breaches of logging rules while economizing monitoring capacity}

As the owner of the forest, the government and the public bear the ultimate consequences of the lessee's violation of logging rules. Leases must therefore provide the means to penalize such behavior. Levying a theoretically attractive waste tax would require intensive on-site monitoring and is therefore highly impractical. Taxes levied on volume harvested play no useful role, except possibly to finance enforcement efforts when the funds are earmarked. The only way to provide the necessary safeguard is to provide for the payment of a guarantee deposit at the beginning of the lease. This amounts to making the terminal payment reflect the value of the forest at the end of the lease conditional on compliance. The forest guarantee bond discussed in this paper combines all these features. Finally, we want to stress that delinking monitoring and tax collection activities helps to avoid the inherent conflicts of interest involved. It also reduces the scope for corruption. If adequate periodical checks are made to curtail abuses, public involvement in monitoring loggers can further contribute to the rigorous enforcement of regulations while public disclosure of violations can provide a powerful reinforcement. 


\section{References}

Bellman, Richard E., 1957, Dynamic Programming (Princeton: Princeton University Press).

Borhan Mohhamad, Bin Johari, and Eswar S. Quash, 1987, "Studies of logging damage due to different methods and intensities of harvesting in hill dipterocarp forests of Peninsular Malaysia," Malaysian Forester, Vol 50, No 1-2.

Bruenig, Eberhard F., 1996, Conservation and management of tropical rainforest: an integrated approach to sustainability, CAB International, Wallingford.

Buschbacher, Robert, J., 1990, "Natural Forest Management in the Humid Tropics: Ecological, Social and Economic Considerations," Ambio, Vol. 19, No. 5, pp. 253258.

Clark, Colin W., 1990, Mathematical Bioeconomics: the Optimal Management of Renewable Resources (John Wiley and Sons: New York).

Cassels, Dan, 1992, "Forested Watershed Controls in N-E Australia as an Interim Model for Other Humid Tropical Forest Environments ," Tropical Forest Update, Vol. 2, No. 2, ITTO.

Contreras-Hermosilla, Arnoldo, 1997, "The 'Cut and Run' Course of Corruption in the Forestry Sector," Journal of Forestry, Vol. 95, No 12.

Deacon, Robert T., 1994, "Deforestation and the Rule of Law in a Cross Section of Countries," Land Economics, Vol. 70, No. 4, pp. 414-430.

- 1995, "Assessing the Relationship between Government Policy and Deforestation," Journal of Environmental Economics and Management, Vol. 28, No. 1, pp. 1-18.

Dykstra, Dennis P. (ed.), 1995, Forest Operations for Sustainable Forestry in the Tropics, Proceedings of a Symposium organized by IUFRO Subject Group S3.05-00 at the XX IUFRO World Congress, 6-12 August 1995, Tampere, Finland; IUFRO and CIFOR.

Environmental Intelligence Agency, 1996, Corporate Power, Corruption and the Destruction of the World's Forests, London.

Faustmann, Martin, 1849, "On the Determination of the Value which Forest Land and Immature Stands Possess for Forestry," English Edition edited by M. Gane as "Martin Faustmann and the Evolution of Discounted Cash Flow," Oxford Institute Paper 42, (1968). 
Gaffney, Mason, 1957, "Concepts of Financial Maturity of Timber and Other Assets," Agricultural Economics Information Series 62, North Carolina State College, Raleigh, N.C.

Harvard Institute for International Development, 1999, "Market based Instruments in China's Environmental Management," Consultant draft final report to the Asian Development Bank, HIID, Cambridge.

Hyde, William, F, and Roger A. Sedjo, 1992, "Managing Tropical Forest: reflections on the rent distribution discussions," Land Economics, Vol. 68, No. 3, pp. 343-350.

ITTO, 1996, "Reduced Impacts, Increased Costs?," Tropical Forest Update, Vol. 6, No.3.

— 1997, "Sustainable Forest Management in Brazil," Tropical Forest Update, Vol. 7, No. 3.

Mitra, Tapan and Henry Y. Wan, 1986, "On the Faustmann Solution to the Forest Management Problem," Journal of Economic Theory, Vol. 40, pp. 229-249.

Munoz-Braz Evaldo and Marcus V.N. D'Oliveira, 1995, "Damage Produced to the Tropical Moist Forest by Planned Harvesting," Commonwealth Forestry Review, Vol. 74, No. 3, pp. 12-27.

Page, John M. (Jr.), Scott R. Pearson, and Hayne E. Leland, 1976, "Capturing Economic Rents from Ghanaian Timber," Food Research Institute Studies, Vol XV, No.1, pp. $25-51$.

Paris, Remi and Ivan Ruzicka, 1991, "Barking up the Wrong Tree: The role of rent appropriation in sustainable tropical forest management," ADB Environment Office, Occasional paper, Manila.

_ 1993 "The Case Against Environmental Taxes for Sustainable Forestry," Journal of Forestry, Vol. 91, No. 4, pp. 22-26.

Paris, Remi, Ivan Ruzicka, and Hugh Speechly, 1994, "Performance Guarantee Bonds for Commercial Management of Natural Forests: early experience from the Philippines," Commonwealth Forestry Review, Vol. 73, No. 2, pp.106-112.

Repetto, Robert, 1988, The Forest for the Trees? Government Policies and the Misuse of Forest Resources (Cambridge University Press: Cambridge MA).

Repetto, Robert, and Malcolm Gillis (eds), 1988, Public Policies and the Misuse of Forest Resources (Cambridge University Press: Cambridge MA). 
Reid, John, W. and Richard E. Rice, 1997, "Assessing Natural Forest Management as a Tool for Tropical Forest Conservation," Ambio, Vol. 26, No. 6, pp. 382-386.

Richardson, Dennis, S., 1992, "Sticks and Carrots in Forest Concession Management," Commonwealth Forestry Review, Vol. 71, No. 3, pp. 167-170.

Vincent, Jeffrey, R., 1993a,"Managing Tropical Forests: comment," Land Economics, Vol. 69, No. 3, pp. 313-318.

__ 1993b, "Depletion and Degradation are not the Same," Journal of Forestry, Vol. 9, No. 4, pp. 24-25.

- , and Theodore Panayotou, 1994, "Tropical Timber Concession Policies," Paper presented to the International Institute of Public Finance.

Weidelt, Hans-Joachim, and Valeriano S. Banaag, 1982, "Aspects of Management and Silviculture of Philippine Dipterocarp Forests," Shriftenreihe der GTZ, Eshborn.

World Bank, 1999, "Five Years After Rio: Innovations in Environmental Policy," Environment Department (World Bank: Washington DC). 